\title{
Letter to the editor: dural reconstruction with a vascularised pleural flap following en bloc resection of a thoracic epithelioid sarcoma: technical note
}

\author{
Alexandre Simonin • Michel Gonzalez • Marc Levivier • \\ John Duff
}

Received: 25 February 2014 / Accepted: 7 March 2014/Published online: 25 March 2014

(C) Springer-Verlag Wien 2014

Dear Editor,

Dural reconstruction is often required in spinal surgery. Large defects after dural resection for certain tumours often require a dural patch closure typically using synthetic or autologous materials.

Various patch materials, including autograft (fat, fascia lata, omentum), modern synthetic materials, allograft, and xenografts such as bovine pericardium, have been used [1]. Each material presents distinct properties, advantages, and risks. At the thoracic level, dural closure and healing are complicated by the negative intrapleural pressure [2]. Previous authors used the fascia lata, intercostal muscle flap [3], or vascularised omental flap $[4,5]$ as an autologous dural substitute for thoracic dural defects. Vascularised flaps have the advantage of an intrinsic blood supply and are autologous, thereby reducing the risk of infection as compared to synthetic materials $[6,7]$.

We report the successful use of a vascularised pleural flap as a dural substitute after en bloc resection of a thoracic epithelioid sarcoma. A 45-year-old woman presented with right-sided mid-intercostal lancinating pain. Her neurological examination was normal. A thoracic spine MRI (Fig. 1, upper left panel) showed a fairly homogeneous enhancing mass at

A. Simonin $(\bowtie) \cdot$ M. Levivier $\cdot$ J. Duff

Neurosurgery, Department of Clinical Neurosciences, Centre

Hospitalier Universitaire Vaudois (CHUV), Lausanne, Switzerland

e-mail: alexandre.simonin@chuv.ch

M. Gonzalez

Thoracic Surgery, Centre Hospitalier Universitaire Vaudois (CHUV), Lausanne, Switzerland the fifth right intercostal space extending medially to the costo-vertebral junction and into the T5 and T6 neural foramen and adjacent epidural space. A combined transthoracic and translaminar approach with the thoracic surgical and neurosurgical team was planned for a radical en bloc resection. A right posterolateral thoracotomy [8] was performed and the latissimus dorsi muscle was detached inferiorly for the muscular flap. The anterior arch of the ribs was exposed at a distance from the tumour. Then, chest wall resection was performed with a section of the 4th to 7 th ribs. Following partial thoracic wall resection with the tumour, the medial margins were exposed by right T5-7 laminectomies using a high-speed drill and extended laterally through the right T4-5 and T7-8 facet joints. The dura was opened at the midline, and the right $\mathrm{T} 4$ through $\mathrm{T} 7$ nerve roots were divided intradurally. The ventral dura was opened longitudinally from $\mathrm{T} 4$ to $\mathrm{T} 7$, and the dural incisions were joined transversely and laterally at the T4 and T7 levels. Partial corpectomies were carried out from the superior end plate of $\mathrm{T} 4$ to the inferior end plate of T7, using a high-speed microdrill and osteotomes. The specimen was then removed en bloc without macroscopic violation of the tumour margins. Due to the large dural defect, an apical vascularised pleural flap, hinged medially, was mobilised and sutured to the dural margins using a running 5-0 prolene suture (Fig. 1, lower panels). This was reinforced with a synthetic dural gel sealant. The latissimus dorsi muscle flap was then mobilised and sutured around the chest wall defect, reinforcing the pleural patch and eliminating the dead space of the defect. Standard closure of the thoracotomy was finally performed. The histopathological diagnosis revealed an epithelioid sarcoma (grade 2). An adjuvant radiotherapy [9] for a total dose of 66 Gy was performed. No trancutaneous leakage or pulmonary fluid collection formed postoperatively. The postoperative MRI done 6 weeks after 
Fig. 1 Upper left panel: Preoperative axial T1 CE MRI through the upper right hemithorax demonstrates an enhancing mass at the fifth right intercostal space extending medially to the costovertebral junction, with a direct invasion of the intervertebral foramen and epidural invasion of the spinal canal. Upper right panel: Postoperative axial T1 CE MRI with the pleural graft in place (arrow). Lower left panel: A pleural flap is mobilised to cover the large dural defect. (1) Dura mater, (2) medulla, (3) vertebral body, (4) visceral pleura, (5) hinged parietal pleural flap, (6) thoracic rib (partially resected). Lower right panel: The pleural flap is sutured to the dural margins with a running suture
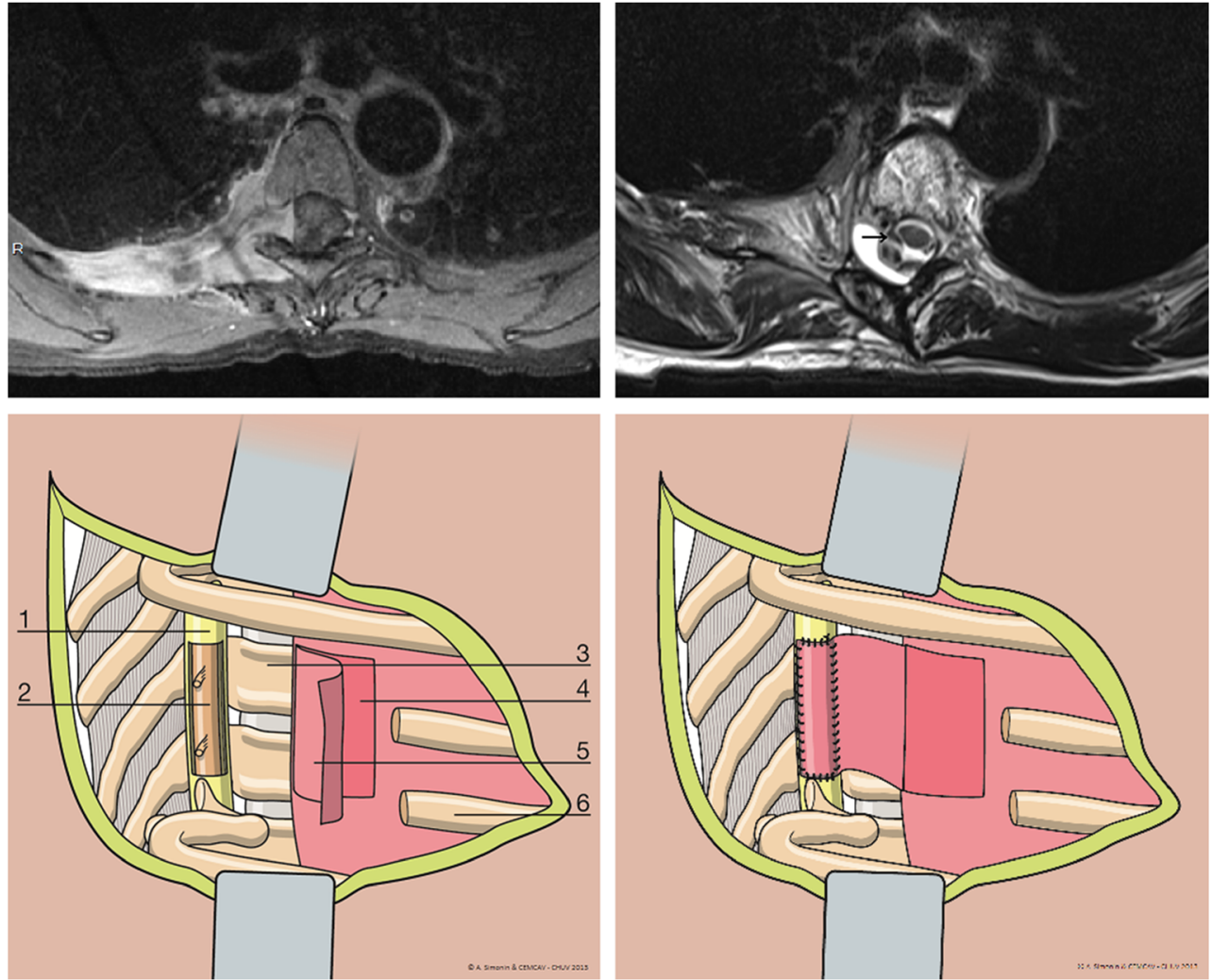

surgery showed the post-resection status of the tumour with the pleural graft in place (Fig. 1, upper right panel). At the 1-year follow-up after surgery, an MRI showed the graft in place, and there was no sign of leakage clinically.

The thoracic region is especially challenging because a dural defect exposes a positive pressure compartment (the subarachnoid space) to a negative pressure compartment (the pleural space) creating an environment favourable for unidirectional movement and fluid accumulation [4, 10]. A vascularised pleural flap has the advantage of its own blood supply, reducing infection risks; it is autologous, which means less tissue reaction, and is close to the dura mater, allowing easy handling within the same operating site.

We describe, to the best of our knowledge for the first time, the successful use of a vascularised pleural flap for repairing a thoracic dural defect following tumour resection. We believe it is a good option in order to achieve a watertight dural closure, which is essential in order to prevent wound breakdown, formation of pseudomeningocele or CSF fistulae associated with infectious complications.

\section{Conflicts of interests None.}

Financial support No special fund contributed to this paper.

\section{References}

1. Finn MA, Faulkner ND, Hetzel SJ, Anderson PA (2011) Spinal duraplasty materials and hydrostasis: a biomechanical study. J Neurosurg Spine 15:422-427

2. Hentschel SJ, Rhines LD, Wong FC, Gokaslan ZL, McCutcheon IE (2004) Subarachnoid-pleural fistula after resection of thoracic tumors. J Neurosurg 100(4 Suppl Spine):332-336

3. Narotam PK, José S, Nathoo N, Taylon C, Vora Y (2004) Collagen matrix (DuraGen) in dural repair: analysis of a new modified technique. Spine 29(24):2861-2867, discussion 2868-9

4. Sahota S, Nassr A, Khan MH, Marsh RW, Moran SL, Arnold PM, Dekutoski MB (2012) Treatment of a thoracic dural-pleural fistula with a vascularized omental flap: a case report. Spine 37(11):E683-E685

5. Levashev YN, Akopov AL, Mosin IV (1999) The possibilities of greater omentum usage in thoracic surgery. Eur J Cardiothorac Surg $15: 465-468$

6. Caroli E, Rocchi G, Salvati M, Delfini R (2004) Duraplasty: our current experience. Surg Neurol 61:55-59

7. Keller JT, Ongkiko CM Jr, Saunders MC, Mayfield FH, Dunsker SB (1984) Repair of spinal dural defects. An experimental study. J Neurosurg 60(5):1022-1028

8. Steck JC, Dietze DD, Fessler RG (1994) Posterolateral approach to intradural extramedullary thoracic tumors. J Neurosurg 81(2):202-205

9. Weisskopf M, Münker R, Hermanns-Sachweh B, Ohnsorge JAK, Siebert C (2006) Epithelioid sarcoma in the thoracic spine. Eur Spine J 15(Suppl 5):S604-S609

10. Krepler P, Windhager R, Toma CD, Kitz K, Kotz R (2003) Dura resection in combination with en bloc spondylectomy for primary malignant tumors of the spine. Spine 28(17):E334-E338 